\title{
Prevalence of Risk of OSAS in Patients Undergoing General Anesthesia in a Private Hospital in Mexico City
}

\author{
Paola Guadalupe Villatoro Portillo ${ }^{1,2}$, Alberto Robles Méndez Hernández ${ }^{1,3^{*}}$, Aurora \\ María Gil Fuentes ${ }^{2}$, Erick Alejandro Ramírez Valencia ${ }^{2}$, Fátima Careli Morado \\ Manríquez $^{2}$, Sara Gabriela González Sánchez ${ }^{2}$, Adriana Díaz-Anzaldúa ${ }^{4}$, María Leonor \\ González Arrieta ${ }^{5}$, Alberto Juan López Bascopé ${ }^{5}$ \\ ${ }^{1}$ Facultad Mexicana de Medicina, Universidad La Salle México \\ ${ }^{2}$ Resident of Anesthesiology, Hospital Ángeles Metropolitano \\ ${ }^{3}$ Departmentof General Surgery, Hospital Ángeles Metropolitano \\ ${ }^{4}$ ClinicalResearch Branch, Instituto Nacional de Psiquiatría Ramón de la Fuente Muñiz \\ ${ }^{5}$ Professor of the Anesthesiology course, Hospital Ángeles Metropolitano
}

*Corresponding Author: Alberto Robles Méndez Hernández, Facultad Mexicana de Medicina, Universidad La Salle México, Departmentof General Surgery, Hospital Ángeles Metropolitano

\begin{abstract}
Obstructive sleep apnea syndrome (OSAS) is characterized by episodes of airway obstruction. In Mexico it is under diagnosed and therefore under-treated. In patients undergoing general anesthesia with this pathology, mortality may increase in the trans and post-anesthetic period due to complications at the respiratory, cardiovascular and nervous levels.
\end{abstract}

Objective: To determine the prevalence of risk of OSAS using the STOP-BANG scale

Material and methods: Observational, prospective, descriptive study carried out March 01 to November 30, 2020 Results Forty patients were included, of which 20 correspond to the male gender, the mean age in women was 50.8 ( \pm 14.4$)$ for men was 49.4 ( \pm 16.88 ), the most common BMI was in the range of 25 to 29.9 . Regarding the classification according to the ASA, mild disease represented $48 \%$ and severe $40 \% .40 \%$ of the total showed a moderate risk of obstructive sleep apnea, in which an association with higher blood pressure was found. $85 \%$ in men and 55\% in women had a moderate risk of OSAS with a score greater than 3 according to the STOP-BANG questionnaire. The postoperative complications most frequently observed was arterial hypertension and desaturation that required oxygen in patients who obtained a high risk of OSAS, it occurred in 2 out of 3 women, while in males 6 out of 8

Conclusions: The prevalence of OSAS in the Mexican population is similar to that reported in the international literature, despite the fact that this study was carried out in a limited sample, it demonstrated a statistical correlation between the score obtained on the STOP-BANG scale with complications in the postoperative period, for which we consider It is important to use the STOP-BANG scale to assess the risk of OSAS in the preoperative period.

Keywords: Obstructive sleep apnea syndrome, postoperative complications, STOP-BANG

\section{INTRODUCTION}

Obstructive sleep apnea syndrome (OSAS) is a common condition characterized by episodes of partial or total airway obstruction, mainly when the patient is asleep.

The prevalence among surgical patients varies between $24-41 \%$ depending on the type of surgery and can exceed $70 \%$ in bariatric surgeries, being more frequent in males, associated mainly with obesity, diabetes, heart disease and advanced age. [1,3,11,14] Regarding the factors that affect due to anesthetic management, it is due to procedures under general anesthesia, which includes difficulty in ventilation, and difficult intubation, opioidbased analgesia and surgical position. [3, 7, 8]

The common clinical picture is snoring, feeling of suffocation, restlessness during sleep, sweating, nícturia, daytime sleepiness. 
The diagnosis is made by polysomnography (gold standard) in which the apnea-hypopnea index is established, however, as it is an expensive and not very accessible study, it is not performed routinely, making it an underdiagnosed pathology, conditioning late complications at the cardiovascular level. pulmonary and nervous. In the patient who will undergo surgery, the diagnosis of OSAS may go unnoticed in the pre-anesthetic evaluation, which can lead to respiratory complications (abnormalities in pulmonary exchange, airway obstruction, hypercapnia, atelectasis) and cardiovascular (systemic and pulmonary hypertension). , arrhythmias, myocardial infarction, and congestive heart failure) during the trans and post-anesthetic period, which can translate into unexpected ICU admissions and prolonged hospital stays. [3, 6,7]

The STOP-BANG scale is a questionnaire that stratifies the risk of suffering from OSAS, which is easy, fast, non-invasive, it was originally developed in the surgical population, but has been validated in many patient populations, it consists of eight independent elements, three are symptoms related to OSAS, three are anatomical measurements (BMI, neck circumference, and high blood pressure) and two are characteristics of the patient (age and sex), obtaining a score to stratify the risk of OSAS into three groups: 0-2 low risk, 3-4 intermediate risk, 5-8 high risk for OSAS.

Given what has already been stated, the purpose of this study is to be able to provide evidence in the Mexican population of which there is little information regarding the prevalence of having the risk of OSAS and its possible complications in the trans-anesthetic and post-anesthetic.

\section{MATERIAL AND METHODS}

Prospective, observational, descriptive study that included 40 Mexican patients over 18 years of age scheduled for elective surgery in a tertiary hospital in Mexico City. The objectives were explained to each of the patients and all of them signed an informed consent; The STOPBANG questionnaire was applied to all patients before surgery between March 01 and November 30, 2020. An initial evaluation that included sociodemographic data was carried out through a format designed for this purpose, with a direct interview with the patient and their relatives. The study was approved by the Ethics and Research Committee of the private hospital. The participation of the subjects was voluntary, and the identification of the participants was kept confidential, identifying the questionnaires with progressive numbers.

Clinical data were collected and analyzed using BMI SPSS version 22 software. Data collected included gender, age, and clinical characteristics. The results of the clinical characteristics were established according to the ASA Physical State Classification System and the STOP-BANG questionnaire. OSAS risk classifications were considered in three categories: low risk, moderate risk, and high risk. In addition, the presence of OSAS risk was considered with a score of 3 or higher in the STOP-BANG questionnaire. The parameters were represented by means and standard deviations. Categorical results were evaluated using crosstabulations. $\mathrm{P}$ values less than 0.05 were considered significant for each test. Statistical tests used in this study included the T test, ANOVA, and Tukey's test, chi square, Fisher's exact test, and logistic regression to determine the differences between the study groups and the factors associated with the risk of apnea.

\section{ReSUlts}

The sample included 40 participants. Two groups were structured according to their gender (female: 20 and male: 20 ). No difference in age or BMI were identified (P-values of 0.77 and 0.75 for age and BMI respectively). Female's mean age was $50.8( \pm 14.4)$ years with a mean BMI of $27.6( \pm 5.92) \mathrm{kg} / \mathrm{m} 2$; for the group of men, the mean age was $49.4( \pm 16.88)$ years and a mean BMI of $26.91( \pm 3.24) \mathrm{kg} / \mathrm{m}^{2}$

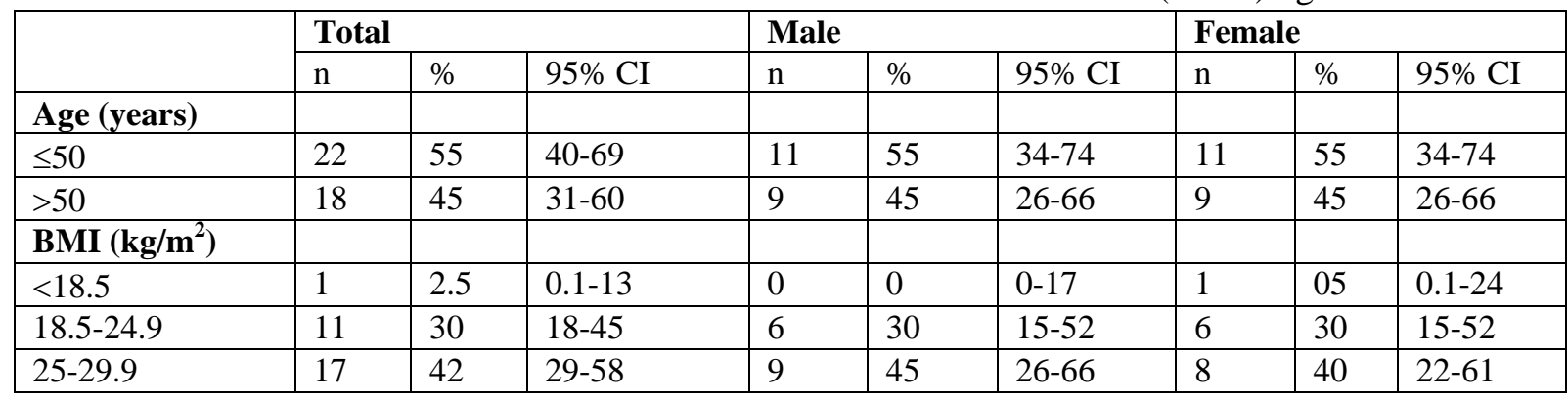


Prevalence of Risk of OSAS in Patients Undergoing General Anesthesia in a Private Hospital in Mexico City

\begin{tabular}{|l|l|l|l|l|l|l|l|l|l|}
\hline$\geq 30$ & 11 & 28 & $16-43$ & 5 & 25 & $11-47$ & 6 & 30 & $15-52$ \\
\hline ASA & & & & & & & & & \\
\hline Healthy & 5 & 12 & $5-26$ & 1 & 5 & $1-24$ & 4 & 20 & $8-42$ \\
\hline Milddisease & 19 & 48 & $33-63$ & 11 & 55 & $34-74$ & 8 & 40 & $22-61$ \\
\hline Severedisease & 16 & 40 & $26-55$ & 8 & 40 & $22-61$ & 8 & 40 & $22-61$ \\
\hline OSA risk & & & & & & & & & \\
\hline Low & 13 & 33 & $19-49$ & 4 & 20 & $6-44$ & 9 & 45 & $23-68$ \\
\hline Moderate & 16 & 40 & $25-57$ & 8 & 40 & $19-64$ & 8 & 40 & $19-64$ \\
\hline Severe & 11 & 27 & $15-44$ & 8 & 40 & $19-64$ & 3 & 15 & $3-38$ \\
\hline
\end{tabular}

Table1: Sample characteristics according to risk groups. BMI: body mass index; ASA: Physical status classification; OSAS risk: Obstructive sleep apnea risk (Stop Bang categories), CI: confidence interval.

Table 1 shows that a large proportion of the sample $(55 \%)$ had 50 years of age or less. The most common BMI category was from 25 to 29.9, considered as overweight, and present in $42 \%$ of the sample. Overweight was more common in men ( $45 \%$ vs $40 \%$ in women), but a BMI of $30 \mathrm{~kg} / \mathrm{m} 2$ or higher, which was considered as obesity, was more common in women (30\% Vs. $25 \%$ in men). Regarding the ASA physical status classification, most patients had a mild disease (48\%), followed by severe disease in $40 \%$, and only $12 \%$ were considered healthy. Most patients $(40 \%)$ had a moderate risk for obstructive sleep apnea (OSA). A high or severe risk was found in $40 \%$ of male individuals as well as in $15 \%$ of the female group. There were no statistically significant differences for BMI (Fisher's exact test $\mathrm{p}=1.00$ ), ASA $(p=0.384)$, or OSA risk $(p=0.141)$ between male and female participants.

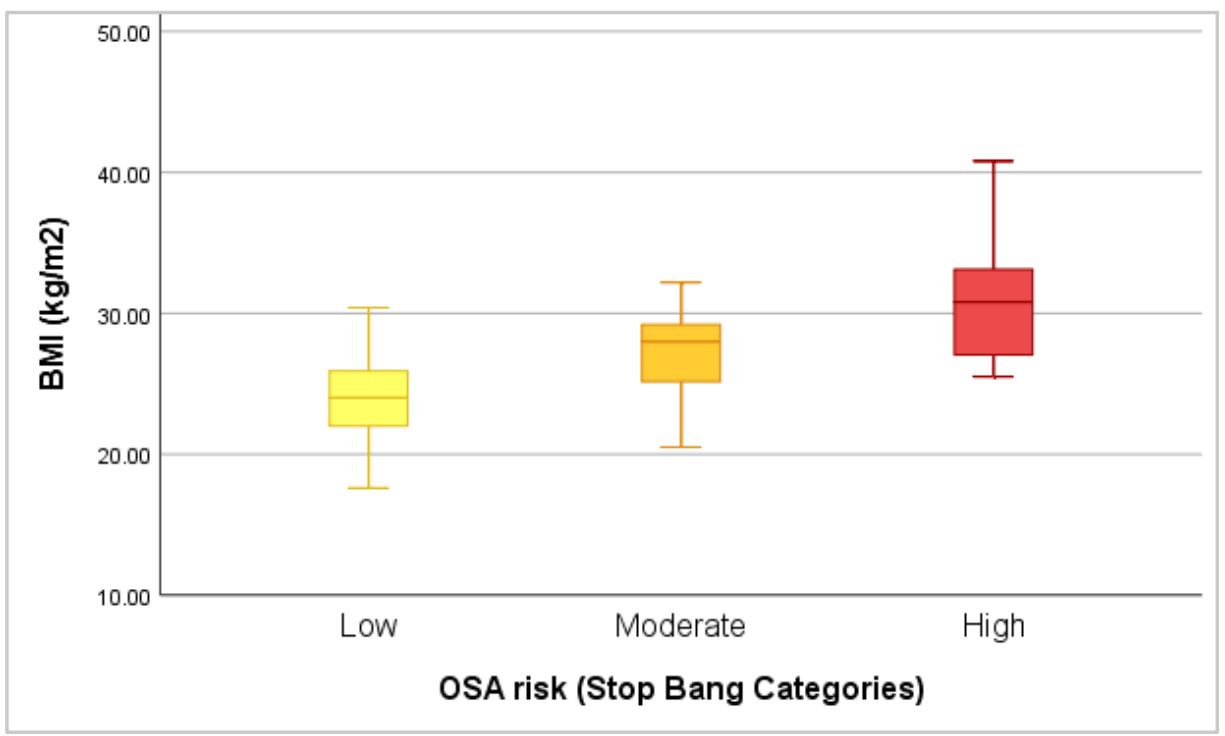

Figure1: Differences in mean body mass index (BMI) according to the OSA risk categories (Stop Bang). $F=11.36, p=0.000143$. Error bar: \pm 1 S.D. Tukey difference between individuals with low and moderate risk: $p=0.042$; between individuals with low and high risk: $p=0.00004$; between individuals with moderate and high risk: $p=0.048$. The central line represents the median of BMI of each OSA risk group. The box contains $50 \%$ of the cases in each group, and the vertical lines the remaining cases.

As indicated in figure 1, as the risk for OSA increased, so did the mean BMI. The lowest mean BMI was found in individuals with a low risk, followed by subjects with a moderate risk. The highest mean BMI was found in patients with a high risk for OSA. The main difference was found when comparing individuals with a low risk for OSA and individuals with a high risk $(\mathrm{p}=0.00004)$. There were only two patients with a BMI higher than $35 \mathrm{~kg} / \mathrm{m}^{2}$. Blood pressure was higher in subjects with a risk for OSA. Mean systolic pressure was $10.37 \mathrm{mmHg}$ higher in individuals with risk for OSA. This group of patients had a mean pressure of $124 \pm 12.05 \mathrm{mmHg}$, while subjects with no risk for OSA had a mean pressure of 114 13.94 (95 CI 1.17-19.57 $\mathrm{mmHg}$ ). Mean diastolic blood pressure was $8.57 \mathrm{mmHg}$ higher in individuals with risk for OSA, who had a mean pressure of $76 \pm 10.72 \mathrm{mmHg}$, compared to those with no risk for OSA, who had a mean pressure of $67 \pm 9.79$ stop (95\% CI $1.27-15.88 \mathrm{mmHg})$, $\mathrm{t}=2.38, \mathrm{p}=0.02)$. 
Mean age was not different in the groups with different risk for OSA (50 years in those with low risk, 49 years in those with moderate risk, and 51 years in those with high risk, $\mathrm{F}=0.04$, $\mathrm{p}=0.95$ ). Mean heart rate was 7 BPM higher in patients with a risk for OSA, who scored 3 or more in Stop Bang (76 \pm 11.14 beats per minute -BPM) than in patients without a risk, who scored 2 or less in Stop Bang (69 BPM \pm 14.05), 95\% CI 1.51-15.32 BPM. However, this difference was not significant $(\mathrm{t}=1.66, \mathrm{p}=0.10)$. The analysis of categories of risk confirmed no difference among those with high (76 BPM),

\begin{tabular}{|l|l|l|l|l|l|l|}
\hline \multicolumn{3}{|l|}{ Male } & \multicolumn{3}{l|}{ Female } \\
\hline Risk & $\mathrm{n}$ & $\begin{array}{l}\text { Mean Neck diameter } \\
(\mathrm{cm}) \pm \text { S.D. }\end{array}$ & $\mathrm{p}$ & $\mathrm{n}$ & $\begin{array}{l}\text { Mean Neck diameter } \\
(\mathrm{cm}) \pm \text { S.D. }\end{array}$ & $\mathrm{p}$ \\
\cline { 1 - 6 } & 12 & $39.69 \pm 3.98$ & 0.003 & 17 & $35.71 \pm 2.62$ & 0.01 \\
\cline { 1 - 5 } & 8 & $44.79 \pm 1.50$ & & 3 & $40.33 \pm 2.08$ & \\
\hline
\end{tabular}

Table2: Differences in mean neck diameter according to OSA risk categories; $p=t$ test significance, $95 \%$ CI 1.98,-8.21 $t=3.44$ for male individuals and $95 \%$ CI 1.24-7.99, $t=2.88$, for female subjects.

The mean neck circumference of male individuals with a high risk for OSA was $5.1 \mathrm{~cm}$ larger than the neck circumference of male individuals with a moderate or low risk for OSA, with a $95 \%$ CI of $1.98-8.21 \mathrm{~cm}$. The mean moderate (76 BPM) or low risk for OSA (69 $\mathrm{BPM}, \mathrm{F}=1.48, \mathrm{p}=0.24)$. These categories were also analyzed for respiratory rate, which was lower in patients with low risk, with a mean of 16.77 breaths per minute, compared to 17.19 in those with a moderate risk, or 17.91 in those with high risk, but this difference was not statistically significant $(\mathrm{F}=0.99, \quad \mathrm{p}=0.38)$. Oxyhemoglobin saturation was also not different among individuals with low (94), moderate (93.63) or high (94.09) risk for OSA $(\mathrm{F}=0.17, \mathrm{p}=0.896)$. neck circumference of female individuals with a high risk for OSA was $4.62 \mathrm{~cm}$ larger than the mean neck circumference of female individuals with low or moderate risk for OSA, with a $95 \%$ CI of 1.24-7.99 cm (table 2).

\begin{tabular}{|l|l|l|}
\hline Gender & Risk for OSA & No risk for OSA \\
\hline Male & $17(85 \%)$ & $3(15 \%)$ \\
\hline Female & $11(55 \%)$ & $9(45 \%)$ \\
\hline
\end{tabular}

Table3: Differences in risk for OSA by gender. Fisher exact test $p=0.0824) . O R=4.64$ (95\% CI: 1.02-21.00). A score of 3 or more in Stop Bang was considered as risk for OSA.

Most of the male patients $(85 \%)$ and $55 \%$ of female patients had a risk for OSA when a score of 3 or more in Stop Bang was considered as risk (table 3 ).

The risk for OSA was not statistically different between those who were ventilated and those who could not be ventilated. Mask ventilation was possible in $87.5 \%$ of the patients $(n=35)$, and there was no difference either by the

\begin{tabular}{|c|c|c|c|c|c|c|}
\hline & \multicolumn{3}{|l|}{ Male } & \multicolumn{3}{|l|}{ Female } \\
\hline Risk & $\begin{array}{l}\text { Complications } \\
\text { Present } \mathrm{n}(\%)\end{array}$ & $\begin{array}{l}\text { Complications } \\
\text { absent } \mathrm{n}(\%)\end{array}$ & $\mathrm{p}$ & $\begin{array}{l}\text { Complications } \\
\text { Present } \mathrm{n}(\%)\end{array}$ & $\begin{array}{l}\text { Complications } \\
\text { absent } \mathrm{n}(\%)\end{array}$ & $\mathrm{p}$ \\
\hline $\begin{array}{l}\text { Low/ } \\
\text { Moderate }\end{array}$ & $1(8 \%)$ & $11(92 \%)$ & 0.004 & $6(35 \%)$ & $11(65 \%)$ & 0.54 \\
\hline High & $6(75 \%)$ & $2(25 \%)$ & & $2(67 \%)$ & $1(33 \%)$ & \\
\hline
\end{tabular}

Table4: Postoperative complications in patients with low or moderate OSA risk versus patients with high risk according to Stop Bang. P: Fisher's exact test significance

Regarding the post anesthesia evaluation, two female patients had apnea ( $10 \%$ of the sample); the same percentage was observed in male patients. As shown in table 4, among the male patients with postoperative complications $(n=7)$, presence or absence of risk for OSA (score cutoff of 3), or by categories comparing those with low/moderate risk and those with high risk (Fisher's exact test $\mathrm{p}=0.60$ ). In addition, the risk for OSA was not different between those who had a difficult intubation and those who did not (Fisher's exact test $\mathrm{p}=1.00$ ). Intubation was difficult in $30 \%$ of the sample $(n=12)$.
$86 \%$ had a high risk for OSA according to the Stop Bang categories $(p=0.004)$. While this significance was not observed in female individuals when using the Stop Bang categories, complications tended to be more 
frequent in individuals with a higher risk for OSA. There were 13 individuals with low risk for OSA; in this low-risk group, only two women and no man had postoperative complications; one of the women had desaturation with oxygen support (recovery to 97\%), and the other one a desaturation without any support needed. Furthermore, in subjects with a moderate risk for OSA, there was only one male patient, out of 8 , who had desaturation, but no oxygen support was needed. Postoperative complications were more commonly present in individuals with high risk for OSA. Two out of three women in this group had a complication, while 6 out of 8 men also had one. From the six men with complications, 3 patients tend to hypertension, 2 had desaturation and received an oxygen supply, and only one had desatuation but no need for oxygen support.

\begin{tabular}{|l|l|l|}
\hline Stop Bang Score & \% of postoperative complications & 95\% CI \\
\hline 6 & 71.60 & $39.19-90.80$ \\
\hline 5 & 58.85 & $35.20-79.02$ \\
\hline 4 & 44.80 & $28.42-62.39$ \\
\hline 3 & 31.53 & $17.68-49.68$ \\
\hline 2 & 20.71 & $8.21-43.28$ \\
\hline 1 & 12.91 & $3.24-39.62$ \\
\hline
\end{tabular}

Table5: Predicted frequency of postoperative complications in individuals with scores from 1 to 6 in Stop Bang. Coefficient $=0.5657$, standard error 0.2543, $p=0.03$, OR=1.76 (CI 95\% 1.07-2.90).

A logistic regression was calculated to predict the presence of postoperative complications based on the risk for OSA estimated with the Stop Bang score. A significant regression was found, indicating that the higher the Stop Bang Score, the higher the prediction of postoperative complications (table 5).

\section{DISCUSSION}

As reported in the international literature, the worldwide prevalence by Singh et al. In adulthood it was $24 \%$ in males and $9 \%$ in females, although our series was not statistically significant, it is striking that it respects the predominance in males, but in very high proportions since $85 \%$ were found in male sex and $55 \%$ female, this could be due to geographical issues and particular characteristics in the Mexican population such as obesity, chronic degenerative diseases, etc.

The increase in body mass index and blood pressure were the individual factors that were related to a higher risk of OSA, being more evident when comparing the low-risk versus high-risk group with $\mathrm{p}=0.048$ and $\mathrm{p}=0.02$ respectively, therefore that in the preoperative assessment of the patient, the alteration of these parameters should be warning signs to rule out OSAS.

As described by Dr. Fajardo in Colombia, the wide and short neck, as well as craniofacial malformations, anatomical nasal obstruction, adenoid hypertrophy are determining factors for the deliberate investigation of OSAS with a sensitivity and specificity of $50-60 \%$ for the diagnosis. ; we found that the greater the neck circumference, the greater the risk of OSA; on average $5.1 \mathrm{~cm}$ higher for males and $4.62 \mathrm{~cm}$ for females the moderate versus low risk group with $\mathrm{p}=0.003$ and $\mathrm{p}=0.01$ respectively, with a $95 \%$ CI for both groups.

A limitation of this study is that some of the analyzes included very small groups, which we consider could have affected the results of some variables such as difficulty for mask ventilation and intubation, since no statistical difference was found between the group with high and low risk of OSAS compared to what has already been described in the literature.

Despite having a limited group of patients, a strong and significant correlation was found between the risk of postoperative complications and the score of the STOP-BANG scale, ranging from $12.91 \%$ to $71.6 \%$ from 1 to 6 points respectively with a relative risk of 1.76 and a $p$ $=0.03$, so we consider that this tool is useful and valid to stratify the risk of OSAS in the Mexican population.

\section{CONCLuSions}

The prevalence of OSAS in the Mexican population is similar to that reported in the international literature, despite the fact that this study was carried out in a limited sample, it demonstrated a significant statistical correlation between the score obtained on the STOP-BANG scale with complications in the postoperative period due to What we consider important to use this scale, which is useful and valid to stratify the risk of OSAS in the preoperative period in Mexican patients; and thus be able to improve the management of chronic diseases, decrease 
postoperative complications and hospital stay, which leads to reducing health costs.

\section{REFERENCES}

[1] Miranda, M. d. (2015). SAOS implicaciones anestesicas. Revista Mexicana de Anestesiología, 5255-5256.

[2] Barrera, M. (2018). Evaluación y manejo anestésico del paciente con SAOS programado para amigdalectomía. Revista Mexicana de Anestesiologia, S9-S10.

[3] Holt, N. R., Downey, G., \& Naughton, M. T. (2019). Perioperative considerations in the management of obstructive sleep apnoea. Medical Journal of Australia, 211(7), 326-332.

[4] Singh, M., Liao, P., Kobah, S., Wijeysundera, D. N., Shapiro, C., \& Chung, F. (2013). Proportion of surgical patients with undiagnosed obstructive sleep apnoea. British Journal of Anaesthesia, 110(4), 629-636.

[5] Fajardo, A., Perea, A. H., \& Hidalgo, P. (2017). Manejo perioperatorio del paciente con síndrome de apnea-hipopnea obstructiva del sueño (SAHOS). Revista Facultad deMedicina, S81-S85.

[6] Mergen, H., Altındağ, B., Zeren Uçar, Z., \& Karasu Kilıçaslan, I. (2019). The Predictive Performance of the STOP-Bang Questionnaire in Obstructive Sleep Apnea Screening of Obese Population at Sleep Clinical Setting. Cureus.110

[7] Tamisier, R., Fabre, F., O’Donoghue, F., Lévy, P., Payen, J.-F., \& Pépin, J.-L. (2018). Anesthesia and sleep apnea. Sleep Medicine Reviews, 40, 79-92.

[8] Melesse, D. Y., Mekonnen, Z. A., Kassahun, H. G., \&Chekol, W. B. (2020). Evidence based perioperative optimization of patients with obstructive sleep apnea in resource limited areas: A systematic review. International Journal of Surgery Open, 23, 23-34.

[9] Diken, Ö. E., Diken, A. İ., Yalçınkaya, A., Gülbay, B., Acıcan, T., Demir, E., Erol, M. E. (2018). Predictive Value of STOP-BANG on OSAS-Related Complications Following Coronary Artery Bypass Grafting. Respiratory Care, 63(10), 1264-1270.

[10] Wolfe, R., \& Pomerantz, J. (2016). Obstructive Sleep Apnea: Preoperative Screening and Postoperative Care. Perioperative Care of Obstructive Sleep Apnea, 263-275

[11] Paez, S., \& Karem, J. (2017). Cuadro clínico del síndrome de apnea-hipopnea obstructiva del sueño (SAHOS). Revista Facultad de Medicina, 29,37.

[12] Nagappa, M., Wong, J., Singh, M., Wong, D., $\&$ Chung, F. (2017). An update on the various practical applications of the STOP-Bang questionnaire in anesthesia, surgery, and perioperative medicine. Current Opinion, 118125.

[13] Nagappa, M., \& Jayadeep, P. (2017). Association of STOP-Bang Questionnaire as a Screening Tool for Sleep Apnea and Postoperative Complications: A Systematic Review and Bayesian Meta-analysis of Prospective and Retrospective Cohort Studies. Anesthesia \& Analgesia, 1-8.

[14] Raalf, C., \& Vries, N. (2017). Obstructive sleep apnea and bariatric surgical guidelines: summary and update. Current Opinion, 1-6.

[15] Kaw, R., Chung, F., Pasupuleti, V., Mehta, J., Gay, P. C., \& Hernandez, A. V. (2012). Metaanalysis of the association between obstructive sleep apnoea and postoperative outcome. British Journal of Anesthesia, 109(6), 897-906.

[16] Anesthesiologists, A. S. (2014). Practice guidelines for the perioperative management of patients with obstructive sleep apnea:. Anesthesiology, 1081-1093.

[17] Goldbert, J. (2019). Preoperative Assessment of Obstructive Sleep Apnea in the Ambulatory Anesthesia Patient:A Survey of Oral and Maxillofacial Surgery Providers. ElServier, 1-8.

[18] Chudeau, N., Raveau, T., Carlier, L., Leblanc, D., Bouhours, G., Gagnadoux, F., Lasocki, S. (2016). The STOP-BANG questionnaire and the risk of perioperative respiratory complications in urgent surgery patients: A prospective, observational study. Anaesthesia Critical Care \& Pain Medicine, 35(5), 347-353.

[19] Lockhat, E., \& Willingham, M. (2013). Obstructive Sleep Apnea Screening and Postoperative Mortality in a Large Surgical Cohort. Sleep Med , 407-415.

[20] Deveraj, U., \& Rajagopala, S. (2017). Undiagnosed Obstructive Sleep Apnea and Postoperative Outcomes: A Prospective Observational Study. Respiration, 18-25.

[21] Liu, F., Liu, L., Zheng, F., Tang, X., Bao, Y., \& Zuo, Y. (2017). Identification of surgical patients at high risk of OSAS using the Berlin Questionnaire to detect potential high risk of adverse respiratory events in post anesthesia care unit. Frontiers of Medicine, 12(2), 189195.

[22] Gokay, P., Tastan, S., \& Orhan, M. E. (2016). Is there a difference between the STOP-BANG and the Berlin Obstructive Sleep Apnoea Syndrome questionnaires for determining respiratory complications during the perioperative period? Journal of Clinical Nursing, 25(9-10), 1238-1252.

[23] Fernandez, A., \& Bartels, K. (2017). Preoperatively Screened Obstructive Sleep Apnea Is Associated With Worse Postoperative 
Prevalence of Risk of OSAS in Patients Undergoing General Anesthesia in a Private Hospital in Mexico City

Outcomes Than Previously Diagnosed Obstructive Sleep Apnea. Respiration and Sleep Medicine, 594-602.

[24] Liao, P., Yegneswaran, B., Vairavanathan, S., Zilberman, P., \& Chung, F. (2009b). Postoperative complications in patients with obstructive sleep apnea: a retrospective matched cohort study. Canadian Journal of Anesthesia/Journal canadien d'anesthésie, 56(11), 819-828.

Citation: Paola Guadalupe Villatoro Portillo, Alberto Robles Méndez Hernández, et.al. Prevalence of Risk of OSAS in Patients Undergoing General Anesthesia in a Private Hospital in Mexico Cit. ARC Journal of Anesthesiology. 2021; 6(1):01-07. DOI: doi.org/ 10.20431/2455-9792.0601001.

Copyright: (C) 2021 Authors. This is an open-access article distributed under the terms of the Creative Commons Attribution License, which permits unrestricted use, distribution, and reproduction in any medium, provided the original author and source are credited. 